\title{
Adventitial inversion technique for type A aortic dissection distal anastomosis
}

\author{
Tatsuya Oda, MD, Kenji Minatoya, MD, PhD, Hiroaki Sasaki, MD, PhD, Hiroshi Tanaka, MD, PhD, \\ Yoshimasa Seike, MD, Tatsuya Itonaga, MD, Yosuke Inoue, MD, and Junjiro Kobayashi, MD, PhD
}

\begin{abstract}
Objective: Anastomosis in dissected aorta management remains challenging. The patent false lumen of remnant aorta influences the growth of the residual aorta after hemiarch replacement. We evaluated the beneficial effect of adventitial inversion technique for distal anastomotic reinforcement of hemiarch replacement in acute type A aortic dissection.
\end{abstract}

Methods: From 2006 to 2014, 90 patients with DeBakey type I aortic dissection who underwent hemiarch replacement for acute type A aortic dissection management at the National Cerebral and Cardiovascular Center were retrospectively analyzed. Patients were divided according to the technique used: the adventitial inversion technique in group A and the original Sandwich method with Teflon felt in group S. Surgical variables and aortic morphology from distal aortic anastomosis were evaluated by computed tomography after surgery.

Results: The mean follow-up time was $2.2 \pm 2.1$ years with a follow-up rate of $91.1 \%$. Cardiopulmonary bypass time was $208.2 \pm 93.9$ minutes in group A and $220.6 \pm 93.9$ minutes in group $\mathrm{S}$; lower body circulatory arrest time was $51.6 \pm 10.2$ minutes in group A and $54.5 \pm 17.8$ minutes in group S. No significant differences were observed between groups. The overall hospital mortality rate was $10.0 \%$. Postoperative false lumen thrombosis rate at proximal descending aorta on enhanced delayed phase computed tomography was significantly higher in group A than in group $\mathrm{S}$.

Conclusions: The adventitial inversion technique may facilitate thrombotic closure of the distal false lumen in acute type A aortic dissection management by hemiarch replacement. (J Thorac Cardiovasc Surg 2016;151:1340-5)

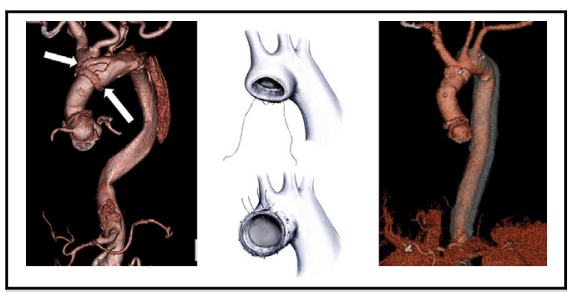

Adventitial inversion versus felt sandwich method in AAD.

\section{Central Message}

The adventitial inversion technique may facilitate thrombotic closure of the distal false lumen.

\section{Perspective}

In hemiarch replacement for AAD, the postoperative false lumen thrombosis rate at proximal descending aorta early postoperative enhanced CT was significantly higher in the adventitial inversion group than in the sandwich method group

See Editorial Commentary page 1346.
Acute type A aortic dissection (AAD) is a surgical emergency with a poor prognosis. For the surgical treatment of AAD, it is essential that the integrity of the aortic wall is restored to achieve secure graft anastomoses, complete hemostasis, and obliteration of the false lumen. A number of reapproximation methods have been introduced; however, the method with the greatest efficacy for thrombosis of the false lumen has yet to be demonstrated. At the time of hemiarch replacement for AAD, patent false lumen at the remnant aorta occasionally is found (Figure 1). The direct forward flow at the distal anastomotic

From the Department of Cardiovascular Surgery, National Cerebral and Cardiovascular Center, Osaka, Japan.

Received for publication March 23, 2015; revisions received Dec 29, 2015; accepted for publication Jan 7, 2016; available ahead of print Feb 6, 2016.

Address for reprints: Kenji Minatoya, MD, PhD, 5-7-1 Fujishiro-dai, Suita, Osaka, 565-8565 Japan (E-mail: minatoya@ncvc.go.jp).

$0022-5223 / \$ 36.00$

Copyright $(2) 2016$ by The American Association for Thoracic Surgery

http://dx.doi.org/10.1016/j.jtcvs.2016.01.018 site may contribute to maintaining the patency of the false lumen left in the remnant aorta. ${ }^{1}$ David and colleagues ${ }^{2}$ reported that a patent false lumen is a major cause of late mortality and morbidity in these patients.

The purpose of this study was to retrospectively evaluate the beneficial effect of the adventitial inversion technique for distal anastomotic reinforcement of hemiarch replacement in AAD.

\section{MATERIALS AND METHODS Patients}

A total of 258 patients underwent surgery for AAD at the National Cerebral and Cardiovascular Center from January 2006 to December 2014.

Scanning this QR code will take you to the article title page.

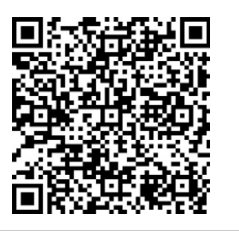




\section{Abbreviations and Acronyms}

$\mathrm{AAD}=$ acute type $\mathrm{A}$ aortic dissection

$\mathrm{CT}=$ computed tomography

$\mathrm{TAR}=$ total arch replacement

Among them, hemiarch replacement was performed in 125 patients. Thirty-five patients with DeBakey type II and retrograde type III aortic dissection were excluded, and 90 patients (mean age, $73.1 \pm 8.5$ years; 35 were male) with DeBakey type I aortic dissection were retrospectively analyzed. Table 1 summarizes the aortic dissection type and preoperative patient characteristics. Organ malperfusion occurred in 22 patients; 13 had cerebral blood flow impairment, 6 had acute myocardial infarction, 3 had renal ischemia, 1 had spinal ischemia, and 1 had leg ischemia. A total of 21 patients went into shock, and 12 patients had cardiac arrest requiring preoperative cardiopulmonary resuscitation.

Patients were divided into 2 groups on the basis of the method of distal anastomotic reinforcement: The adventitial inversion technique was used in group A $(\mathrm{n}=36)$, and the original sandwich method with Teflon felt was used in group $\mathrm{S}(\mathrm{n}=54)$ (Figure 2). No significant difference in age, sex, preoperative shock or frequency of preoperative thrombosed dissection, or organ malperfusion was observed between the 2 groups (Table 1). Some surgeons started to use the adventitial inversion technique in 2006. However, the sandwich technique also was used by other surgeons according to preference for a while. The initial experiences of the adventitial inversion were found to be impressive. Since 2013, all patients have received the adventitial inversion technique. Selection of either technique is not related to the anatomy or dissection morphology. The frequency of the false lumen thrombosis at the proximal descending aorta and the diameter of the descending aorta were evaluated retrospectively in 81 patients with contrast-enhanced computed tomography (CT) imaging (group A, $\mathrm{n}=33$; group $\mathrm{S}, \mathrm{n}=48$ ). False lumen thrombosis was measured by postoperative contrast-enhanced CT imaging before discharge. The diameter of descending aorta was measured by plain CT 1 year after operation with a mean follow-up of $0.9 \pm 0.3$ years. Use of these data for research was approved by the National Cerebral and Cardiovascular Center Institutional Review Boards.

\section{Operation}

All operations were performed on an emergency basis. Extracorporeal circulation was instituted by placement of arterial cannulae in the femoral and right axillary artery, venous cannulae in the superior vena cava and inferior vena cava, and a left ventricular venting cannula via the right superior pulmonary vein. Once moderate or deep hypothermia was achieved, retrograde cardioplegia was induced and the ascending aorta was opened No aortic clamps were used; under circulatory arrest, the primary tear was resected whether in the ascending aorta or transverse arch. Antegrade selective cerebral perfusion was used in all cases and performed through a distal part of right axillary artery after clamping the base of brachiocephalic artery, with a balloon-tipped cannula inserted directly in the left common carotid artery and left subclavian artery.

\section{Distal Aortic Reinforcement and Anastomosis}

Group A received the adventitial inversion technique (Figure 2). The adventitia was trimmed to $1.0 \mathrm{~cm}$ longer than the level of the intimal edge. The redundant adventitia then was inverted into the aortic lumen and tacked to the luminal surface of the intima using 5-0 polypropylene running sutures at the proximal aortic arch level.

Group S received the sandwich method (Figure 2). Teflon felt was placed outside the adventitia and inside the intima. The sandwich anastomosis was reinforced using 2 layers of 4-0 polypropylene interrupted mattress sutures.

The reinforced aorta was then sutured end-to-end to a Dacron tubular graft using 4-0 polypropylene continuous sutures. Biological glue was applied to the distal anastomosis and not used for the reinforcement of aortic layers or obliteration of the false lumen in either technique.

\section{Proximal Reinforcement and Anastomosis}

After completion of the distal anastomosis, the arterial cannula was shifted to the prosthetic graft and cardiopulmonary bypass was reconstituted. The ascending aorta was transected at a level 1 to $2 \mathrm{~cm}$ distal to

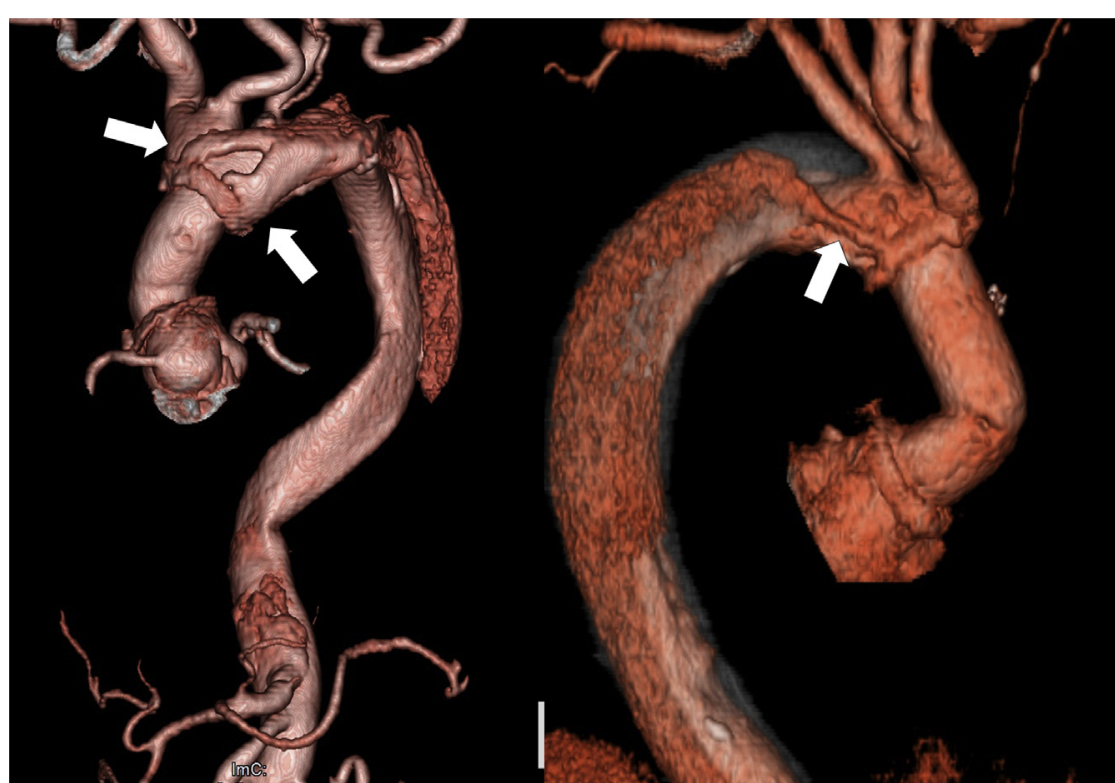

A

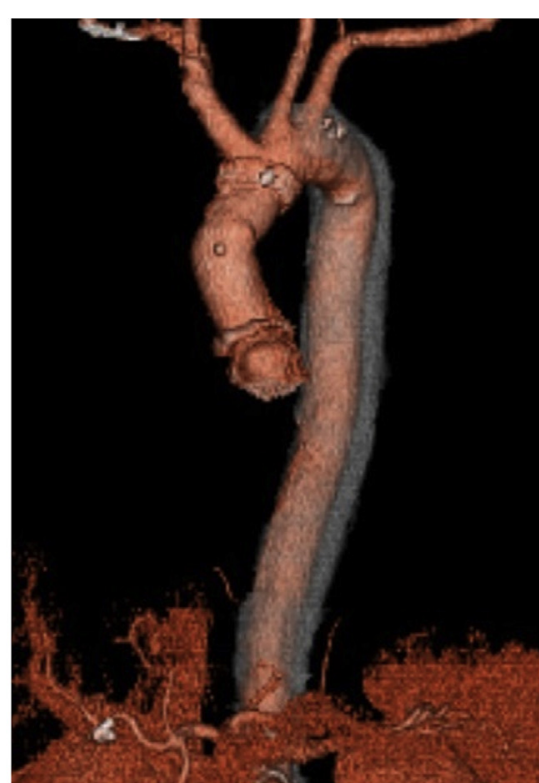

B

FIGURE 1. Postoperative 3-dimensional enhanced CT. A, Arrows indicate postoperative false lumen patency at remnant aorta. B, False lumen on the arch remains thrombosed with effective aortic reinforcement. 
TABLE 1. Patients' characteristics

\begin{tabular}{|c|c|c|c|c|}
\hline & Total & Group A (adventitial inversion) & Group S (sandwich method) & $P$ value \\
\hline No. & 90 & 36 & 54 & \\
\hline Mean age, y (range) & $73.1 \pm 8.5(54-90)$ & $74.2 \pm 8.6$ & $72.6 \pm 8.7$ & .338 \\
\hline Male & $35(38.9)^{*}$ & $11(30.6)$ & $24(44.4)$ & .180 \\
\hline Marfan syndrome & $1(1.1)$ & 0 & $1(1.9)$ & .592 \\
\hline Preoperative shock & $21(23.3)$ & $10(27.8)$ & $11(20.4)$ & .799 \\
\hline Preoperative CPA & $12(13.3)$ & $4(11.1)$ & $8(14.8)$ & .890 \\
\hline Thrombosed type dissection & $31(34.4)$ & $10(27.8)$ & $21(38.9)$ & .108 \\
\hline Organ malperfusion & $22(24.4)$ & $11(30.6)$ & $11(20.4)$ & .286 \\
\hline Cerebral & $13(14.4)$ & $8(22.2)$ & $5(9.3)$ & .092 \\
\hline Coronary & $6(6.7)$ & $2(5.6)$ & $4(7.4)$ & .724 \\
\hline Kidney & $3(3.3)$ & $2(5.6)$ & $1(1.9)$ & .345 \\
\hline Spinal cord & $1(1.1)$ & $1(2.8)$ & 0 & .223 \\
\hline Leg & $1(1.1)$ & 0 & $1(1.9)$ & .412 \\
\hline \multicolumn{5}{|l|}{ Location of primary tear } \\
\hline Aortic root & $2(2.2)$ & $1(2.8)$ & $1(1.9)$ & .998 \\
\hline Ascending aorta & $88(97.8)$ & $35(97.2)$ & $53(98.1)$ & .998 \\
\hline
\end{tabular}

To compare parameters between the 2 groups, Mann-Whitney $U$ test was used. $C P A$, Cardiopulmonary arrest. *Numbers in parentheses are percentages.

the sinotubular junction. Proximal reinforcement was performed with Teflon felt outside and biological glue within the false lumen using 4-0 polypropylene running sutures. Root replacement was performed in patients with severe root dilatation or with entry in the aortic root. The reinforced aorta was then sutured end-to-end to a Dacron tubular graft using 4-0 polypropylene continuous sutures.

\section{Definitions}

We evaluated the preoperative and postoperative false lumen thrombosis on delayed enhanced CT. The amount of bleeding was defined as the suction volume between weaning from cardiopulmonary bypass and chest closure. Shock was defined as clinical evidence of peripheral hypoperfusion with a systolic blood pressure less than $90 \mathrm{~mm} \mathrm{Hg}$. Transfusion

\section{group A : Adventitial inversion technique}

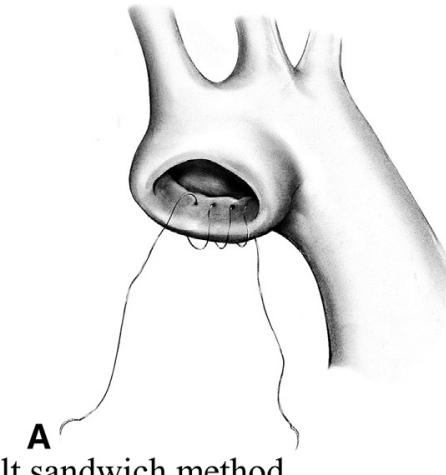

group S: Felt sandwich method

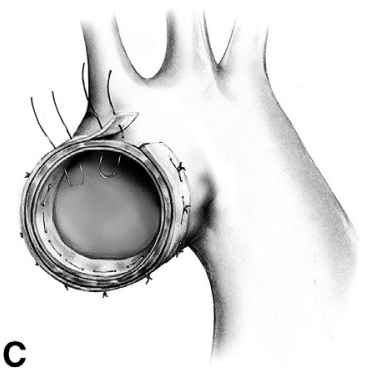

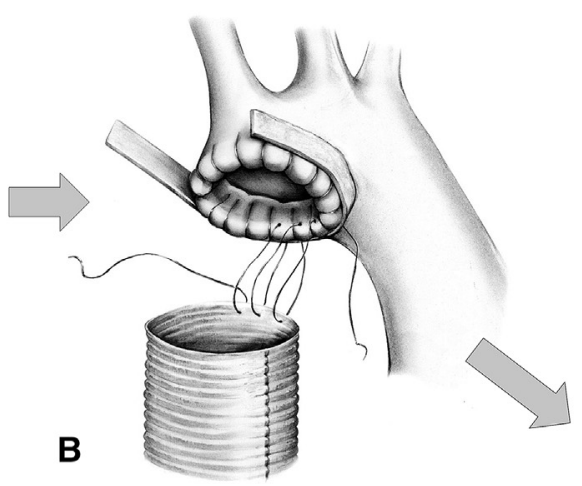

B
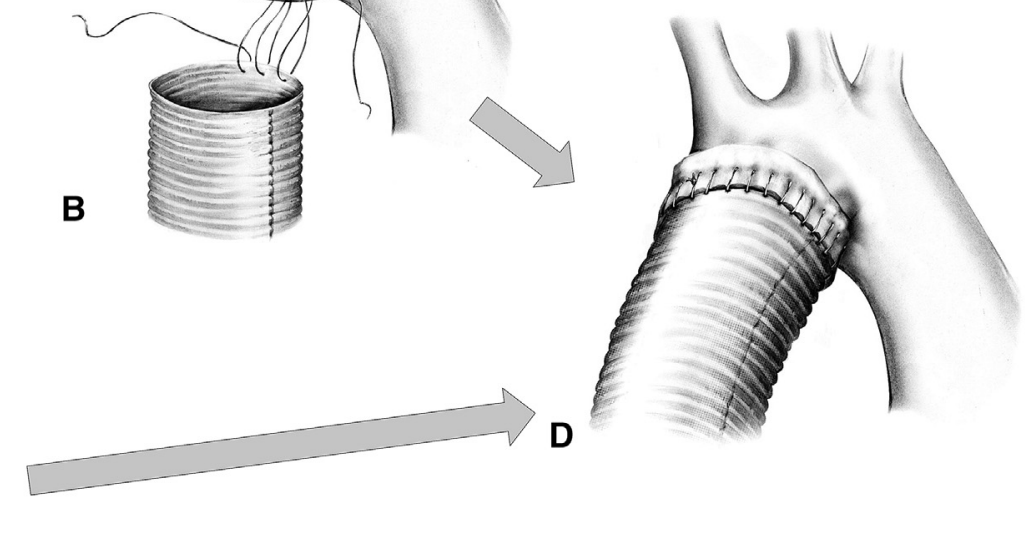

FIGURE 2. Aortic reinforcement and distal anastomosis. A, The adventitia is trimmed to $1.0 \mathrm{~cm}$ longer than the level of the intimal edge. The redundant adventitia is then inverted into the aortic lumen and tacked to the luminal surface of the intima using 5-0 polypropylene running sutures at the level of the proximal aortic arch. B, The reinforced aorta is sutured end-to-end to a Dacron tubular graft using 4-0 polypropylene continuous suturing. The 4-0 polypropylene suture line is internal to the previous 5-0 polypropylene suture line to reduce the needle hole. C, Teflon felt is placed external to the adventitia and internal to the intima. The sandwich anastomosis is reinforced with 2 layers of 4-0 polypropylene interrupted mattress sutures. D, The reinforced aorta was then sutured end-to-end to a Dacron tubular graft using 4-0 polypropylene continuous sutures. 
TABLE 2. Operative variables

\begin{tabular}{|c|c|c|c|c|}
\hline & Total & Group A & Group S & $P$ value \\
\hline No. & 90 & 36 & 54 & \\
\hline Operation time (min) & $399.3 \pm 157.4$ & $376.4 \pm 167.8$ & $417.0 \pm 148.5$ & .080 \\
\hline CPB time (min) & $215.3 \pm 94.3$ & $208.2 \pm 93.9$ & $220.6 \pm 93.9$ & .327 \\
\hline Cardiac arrest time (min) & $122.9 \pm 51.2$ & $118.6 \pm 46.6$ & $125.1 \pm 53.7$ & .469 \\
\hline Lower body circulatory arrest time (min) & $53.6 \pm 15.2$ & $51.6 \pm 10.2$ & $54.5 \pm 17.8$ & .923 \\
\hline Lowest tympanic temperature $\left({ }^{\circ} \mathrm{C}\right)$ & $23.4 \pm 2.4$ & $23.4 \pm 2.4$ & $23.3 \pm 2.5$ & .723 \\
\hline Surgical bleeding $(\mathrm{mL})$ & $2856 \pm 1873$ & $2492 \pm 1612$ & $2892 \pm 2076$ & .435 \\
\hline Median volume of packed red blood cells (U) (range) & $22(6-110)$ & $22(6-48)$ & $22(8-110)$ & .717 \\
\hline Median volume of packed FFP (U) (range) & $29(8-118)$ & $34(8-95)$ & $24(8-118)$ & .116 \\
\hline Median volume of packed platelet (U) (range) & $40(0-130)$ & $40(10-75)$ & $40(0-130)$ & .081 \\
\hline Concomitant procedures & $14(15.6)$ & $5(13.9)$ & $9(16.7)$ & .750 \\
\hline CABG & $7(7.8)$ & $1(2.8)$ & $5(9.3)$ & \\
\hline Aortic valve replacement & $2(2.2)$ & 0 & $2(3.7)$ & \\
\hline Root replacement & $8(8.9)$ & $5(13.9)$ & $3(5.6)$ & \\
\hline Conversion to TAR & $3(3.3)$ & 0 & $3(5.6)$ & .151 \\
\hline Reexploration for surgical bleeding & $13(14.4)$ & $5(13.9)$ & $8(14.8)$ & .890 \\
\hline Hospital death & $9(10.0)$ & $2(5.6)$ & $7(13.0)$ & .249 \\
\hline \multicolumn{5}{|l|}{ Major adverse event } \\
\hline \multicolumn{5}{|l|}{ Neurologic } \\
\hline Stroke & $6(6.7)$ & $2(5.6)$ & $4(7.4)$ & .724 \\
\hline Paraplegia & $1(1.1)$ & $1(2.8)$ & 0 & .223 \\
\hline \multicolumn{5}{|l|}{ Cardiac } \\
\hline Acute myocardial infarction & $1(1.1)$ & 0 & $1(1.9)$ & .412 \\
\hline Heart failure & $3(3.3)$ & $1(2.8)$ & $2(3.7)$ & .806 \\
\hline Respiratory failure* & $7(7.8)$ & $1(2.8)$ & $6(11.1)$ & .148 \\
\hline Permanent hemodialysis & $1(1.1)$ & 0 & $1(1.9)$ & .412 \\
\hline
\end{tabular}

Group A: adventitial inversion. Group S: sandwich method. Packed red blood cells, 1 unit: $140 \mathrm{~mL}$; packed fresh-frozen plasma, 1 unit: $120 \mathrm{~mL}$; packed platelet, 10 units: $200 \mathrm{~mL}$. Numbers in parentheses are percentages. To compare parameters between the 2 groups, Mann-Whitney $U$ test was used. $C P B$, Cardiopulmonary bypass; $F F P$, fresh-frozen plasma; $C A B G$, coronary artery bypass grafting; $T A R$, total arch replacement. *Respiratory failure means postoperative pneumonia, pneumothorax, and tracheotomy.

amounts were defined as over the intraoperative interval and 24 hours after leaving the operation room.

\section{Statistical Analyses}

Continuous data obtained in this study are expressed as the mean \pm standard deviation (range). All statistical analyses were performed using PASW Statistics 20 software (SPSS Inc, Chicago, Ill). Survival analysis was performed using the Kaplan-Meier method. A log-rank test was applied for comparisons between time-related variables. To compare parameters between the 2 groups, the Mann-Whitney $U$ test was used according to the characteristics of the variables.

\section{RESULTS}

The mean follow-up time was $2.2 \pm 2.1$ years with a follow-up rate of $91.1 \%$. Intraoperative variables were evaluated in all patients (Table 1). No significant differences in operative time, cardiopulmonary bypass time, cardiac arrest time, lower body circulatory arrest time, or lowest tympanic temperature were observed between the 2 groups. The mean volume of packed red blood cells administered was $25.1 \pm 11.6$ units in group A and $29.2 \pm 19.1$ units in group S, with no significant difference observed between groups. Conversion to total arch replacement (TAR) during the same operation was performed in 3 patients $(5.6 \%)$ in group $\mathrm{S}$ because of uncontrollable bleeding from the distal anastomosis. No patients required conversion to TAR in group A.

The overall hospital mortality rate was $10.0 \%$ (9/90; group A, 2/36, 5.6\%; group $\mathrm{S}, 7 / 54,13.0 \% ; P=.249$ ). Surgical complications are listed in Table 2. There were 6 strokes: 2 $(5.6 \%)$ in group $\mathrm{A}$ and $4(7.4 \%)$ in group $\mathrm{S}(P=.724)$.

TABLE 3. Postoperative computed tomography examination

\begin{tabular}{|c|c|c|c|c|}
\hline & Total & Group A & Group S & $P$ value \\
\hline No. & 81 & 33 & 48 & \\
\hline Frequency of false lumen thrombosis at proximal descending aorta & $51(63.0)^{*}$ & $26(78.8)$ & $25(52.1)$ & .026 \\
\hline Diameter of descending aorta $(\mathrm{mm})$ & $36.0 \pm 5.7$ & $34.5 \pm 5.2$ & $37.6 \pm 5.7$ & .051 \\
\hline No evaluation & 9 & 3 & 6 & \\
\hline
\end{tabular}

Group A: adventitial inversion. Group S: sandwich method. Three patients requiring conversion to TAR were excluded. False lumen thrombosis was measured by postoperative contrast-enhanced CT imaging before discharge. Diameter of descending aorta was measured by plain CT 1 year after operation with a mean follow-up of $0.9 \pm 0.3$ years. To compare parameters between the 2 groups, Mann-Whitney $U$ test was used. *Numbers in parentheses are percentages. 
Paraplegia remained after surgery in 1 patient who had spinal cord ischemia because of malperfusion preoperatively.

A total of 81 of 90 patients had postoperative contrastenhanced CT imaging before discharge (group A, $\mathrm{n}=33$; group $S, n=48$ ). The frequency of false lumen thrombosis in the proximal descending aorta was significantly higher in group A than in group S (group A, 78.8\%; group S, $47.9 \%$; $P=.026$ ). The postoperative diameter of descending aorta by plain CT 1 year after operation with a mean follow-up of $0.9 \pm 0.3$ years was $34.5 \pm 5.2 \mathrm{~mm}$ in group $\mathrm{A}$ and $37.6 \pm 5.7 \mathrm{~mm}$ in group $\mathrm{S}(P=.051)$ with no significant differences observed between the 2 groups (Table 3 ).

The overall 1- and 3-year survivals were $94.6 \%$ and $94.6 \%$ in group $\mathrm{A}$ and $80.1 \%$ and $77.8 \%$ in group $\mathrm{S}$, respectively, with no significant differences observed between groups $(P=.053)$ (Figure 3).

During follow-up, 1 patient in group $S$ required stent grafting for a dissected descending aortic aneurysm 3 years after hemiarch replacement. No patients in group A required arch or descending aortic repeat operations during the follow-up period (Figure 3).

\section{DISCUSSION}

The management of AAD is technically challenging because of fragility of the dissected aortic wall. The majority of patients with type A aortic dissection have a persistent false lumen after replacement of the ascending aorta. ${ }^{3}$ Bachet and colleagues ${ }^{1}$ and Halstead and colleagues ${ }^{4}$ reported that a patent false lumen influenced the growth of the residual aorta after ascending aortic replacement and that directed forward flow at the distal anastomotic site contributed to the patency of the false lumen left in the remnant aorta. David and colleagues ${ }^{2}$ found that a patent false lumen was a major cause of late mortality and morbidity in these patients. Tanaka and colleagues ${ }^{5}$ demonstrated that reoperation after ascending aortic replacement for acute aortic dissection tended to involve extensive thoracic aortic replacement because of excessive enlargement of the aortic arch and proximal descending aorta.

Thus, secure reinforcement of the dissected aortic wall at anastomotic sites is essential. ${ }^{6,7}$ Various techniques have been developed attempting to improve patient outcomes. Conventionally, the aortic wall is reconstructed by reapproximation of the dissected aortic layers using Teflon felt reinforcement. ${ }^{8}$ Biologic glues, such as gelatinresorcine-formaline glue and, more recently, serum albumin glutaraldehyde tissue adhesive (BioGlue, CryoLife, Inc, Kennesaw, Ga), have been used to obliterate the false lumen and secure graft anastomoses in aortae that have become fragile because of the dissection process. ${ }^{1}$ However, several complications have been reported with these procedures. Matsuura and colleagues ${ }^{9}$ reported a case of stenosis of the proximal anastomotic site caused by an internal felt strip from surgery for AAD. Biologic glues have been associated
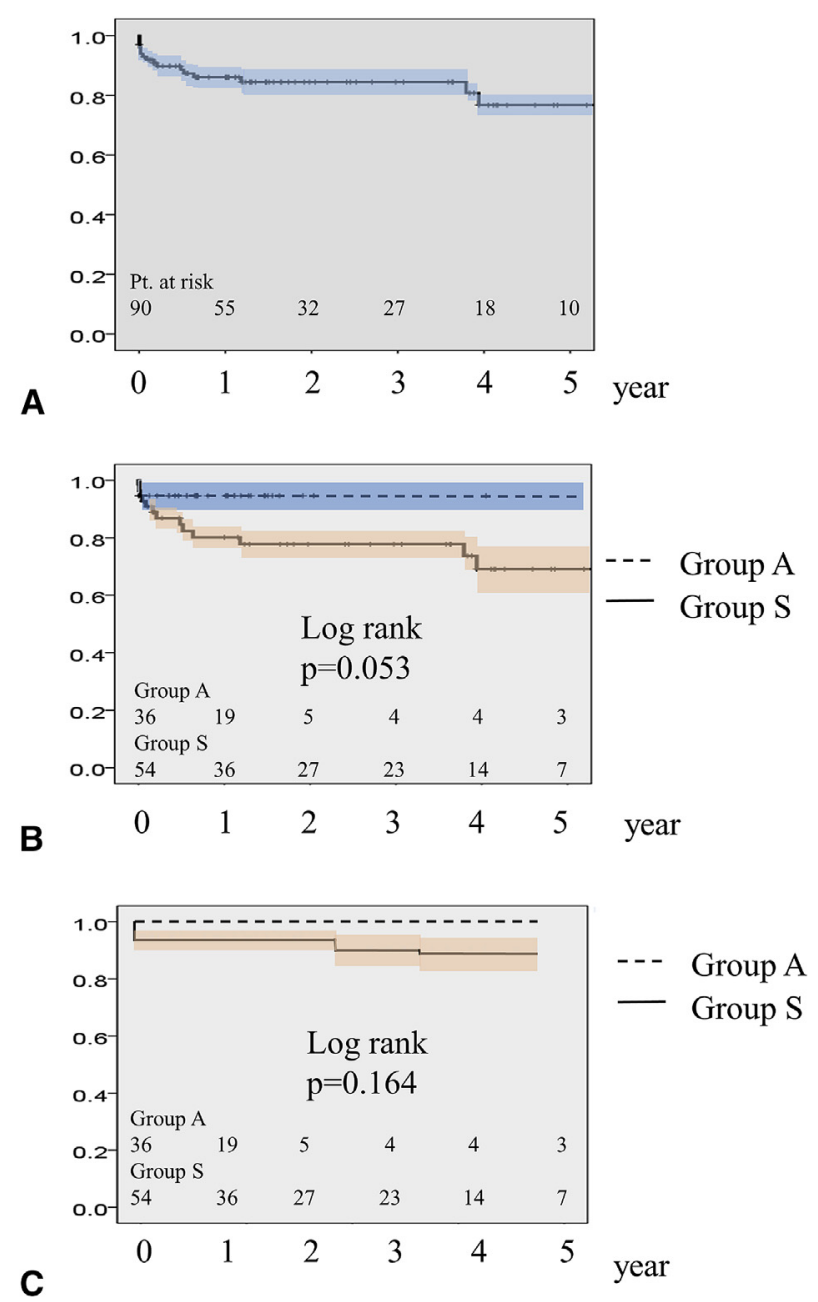

FIGURE 3. A, Kaplan-Meier curves showing overall survival. Shaped areas represent $95 \%$ confidence limits. B, Survival between groups. Group A: adventitial inversion. Group S: sandwich method. Shaped areas represent $95 \%$ confidence limits. C, Aortic arch or descending aortic reoperation-free rate. During follow-up, 1 patient in group $\mathrm{S}$ required stent grafting for descending aortic aneurysm 3 years after initial operation. Shaped areas represent $95 \%$ confidence limits.

with cerebral and coronary embolization, persistent patent false lumen, and tissue necrosis leading to redissection or pseudoaneurysm formation. ${ }^{10-16}$

The adventitial inversion technique was first reported in 1995 by Floten and colleagues, ${ }^{17}$ who aimed at addressing bleeding because of tissue friability in acute aortic dissection. In 1998, Garcia-Rinaldi and colleagues ${ }^{18}$ confirmed that this technique was safe and efficacious for the surgical treatment of acute aortic dissection. Tanaka and colleagues ${ }^{19}$ reported the adventitial inversion technique for distal aortic reinforcement in hemiarch replacement induced postoperative thrombosis of the false lumen in the arch and proximal descending aorta in all 12 cases.

In our study, we evaluated 90 patients who had undergone hemiarch replacement for Stanford type A acute aortic 
dissection. At distal anastomotic reinforcement, the adventitial inversion technique was performed in 36 patients and the sandwich method was performed in 54 patients. In several patients undergoing the sandwich method, we had to struggle to control the anastomosis site bleeding caused by expansion of the false lumen. Among them, 3 patients in the sandwich method group required replacement of the entire arch after initial hemiarch replacement during the same operation because of rupture of the false lumen. In contrast, no patients in the adventitial inversion group required re-replacement of the entire arch after hemiarch replacement. When we adopted open distal anastomosis at circulatory arrest in hemiarch replacement, the aorta inside can be inspected perfectly until distal arch. We believe we do not miss any intimal tear in the arch. When we found any tear in the aortic arch, we did not hesitate to perform arch replacement. We supposed the sandwich method increases the thickness of the suture margin, which might require a large needle and heavy sutures; 4-0 Prolene was used in the sandwich method and 5-0 Prolene was used in the inversion method for the reinforcement of the stump. The adventitia is thinner, softer, and cohesive. The behavior of the adventitia might minimize the needle hole. Although the felt strip was placed superficially, it could be in in less close contact with the surface of the aortic wall because of the nature of the material. Thus, the risk of false lumen patency at the anastomosis site would be increased. This may be one reason that the patient in the sandwich method group was associated with a high incidence of conversion to TAR.

The frequency of thrombosis of the proximal descending aorta on enhanced CT was significantly higher in the adventitial inversion group than in the sandwich method group ( $78.8 \%$ and $47.9 \%$, respectively, $P=.026$ ), although no significant difference was observed in the postoperative diameter of the descending aorta between the 2 groups.

\section{Study Limitations}

Several limitations of our study should be recognized. This was a single-center retrospective study. Because of the small population and short follow-up duration, it is difficult to extrapolate the influence of technique on long-term outcomes. The occurrence of reoperation was infrequent, and therefore it was not possible to fully examine risk factors for reoperation.

\section{CONCLUSIONS}

We propose that the adventitial inversion technique may facilitate thrombotic closure of the distal false lumen when managing AAD.

\section{Conflict of Interest Statement}

Authors have nothing to disclose with regard to commercial support.

\section{References}

1. Bachet J, Goudot B, Dreyfus G, Banfi C, Ayle NA, Aota M, et al. The proper use of glue: a 20-year experience with the GRF glue in acute aortic dissection. J Card Surg. 1997; 12:243-53.

2. David TE, Armstrong S, Ivanov J, Barnard S. Surgery for acute type A aortic dissection. Ann Thorac Surg. 1999;67:1999-2001.

3. Yamaguchi T, Guthaner DF, Wexler L. Natural history of the false channel of type A aortic dissection after surgical repair: CT study. Radiology. 1989;170: 743-7.

4. Halstead JC, Meier M, Etz C, Spielvogel D, Bodian C, Wurm M, et al. The fate of the distal aorta after repair of acute type A aortic dissection. J Thorac Cardiovasc Surg. 2007; 133:127-35.

5. Tanaka H, Okada K, Kawanishi Y, Matsumori M, Okita Y. Clinical significance of anastomotic leak in ascending aortic replacement for acute aortic dissection. Interact Cardiovasc Thorac Surg. 2009;9:209-13.

6. Gerbode F, Semb GS, Hill JD, Kerth WJ. Aneurysms of the ascending aorta. A method of reconstructing the aortic root. Ann Thorac Surg. 1966;2:525.

7. Cachera JP, Vouhe PR, Loisance DY, Menu P, Poulain H, Bloch G, et al. Surgical management of acute dissections involving the ascending aorta. J Thorac Cardiovasc Surg. 1981;82:576-84.

8. Svensson LG, Crawford ES, Hess KR, Coselli JS, Safi HJ. Dissection of the aorta and dissecting aortic aneurysms. Improving early and long-term surgical results. Circulation. 1990;82:IV24-38.

9. Matsuura K, Ogino H, Minatoya K, Sasaki H. Aortic stenosis caused by the felt strip used in repair for acute aortic dissection. Interact Cardiovasc Thorac Surg. 2004;3:41-3.

10. Hoschtitzky JA, Crawford L, Brack M, Au J. Acute coronary syndrome following repair of aortic dissection. Eur J Cardiothorac Surg. 2004;26:860-2.

11. Mastroroberto P, Chello M, Onorati F, Renzulli A. Embolisation, inflammatory reaction and persistent patent false lumen: is biological glue really effective in repair of type A aortic dissection? Eur J Cardiothorac Surg. 2005;27:529-32.

12. Fukunaga S, Karck M, Harringer W, Cremer J, Rhein C, Heverich A. The use of gelatin-resorcin-formalin glue in acute aortic dissection type A. Eur J Cardiothorac Surg. 1999; 15:564-70.

13. Bingley JA, Gardner MA, Stafford G, Mau TK, Pohlner PG, Tam RK, et al. Late complications of tissue glues in aortic surgery. Ann Thorac Surg. 2000;69: 1764-8.

14. Kazui T, Washiyama N, Bashar AH, Terada H, Suzuki K, Yamashita K, et al. Role of biologic glue repair of proximal aortic dissection in the development of early and midterm redissection of the aortic root. Ann Thorac Surg. 2001;72:509-14.

15. Suehiro K, Hata T, Yoshitaka H, Tsushima Y, Matsumoto M, Hamanaka S, et al Late aortic root redissection following surgical treatment for acute type A aortic dissection using gelatin-resorcin—-formalin glue. Jpn J Thorac Cardiovasc Surg. 2002;50:195-200.

16. Von Oppell UO, Karani Z, Brooks A, Brink J. Dissected aortic sinus repaired with gelatin-resorcin-formaldehyde (GRF) glue are not stable on follow up. J Heart Valve Dis. 2002;11:249-57.

17. Floten HS, Ravichandran PS, Furnary AP, Gately HL, Starr A. Adventitial inversion technique in repair of aortic dissection. Ann Thorac Surg. 1995;59:771-2.

18. Garcia-Rinaldi R, Carballido JC, Mojica J, Soltero ER, Curcic S, Barcelo J, et al. Surgical treatment of aortic dissections: initial experience with the adventitial inversion technique. Ann Thorac Surg. 1998;65:1255-9.

19. Tanaka K, Morioka K, Li W, Yamada N, Takamori A, Handa M, et al. Adventitial inversion technique without the aid of biologic glue or Teflon buttress for acute type A aortic dissection. Eur J Cardiothorac Surg. 2005;28:864-9.

Key Words: adventitial inversion, aortic dissection, aortic reinforcement, felt sandwich, hemiarch replacement 